Proceedings

\title{
C3A Epithelium Cells Directly Cultured on High- Dielectric Constant Material for Light-Addressable Potentiometric Sensor ${ }^{+}$
}

\author{
Po-Yen Lin 1, Yu-Jing Lin ${ }^{1}$, Yu-Ping Chen ${ }^{1}$, Hui-Ling Liu ${ }^{2}$, Tsung-Ru Wu ${ }^{3}$, Hsin-Chih Lai ${ }^{3}$, \\ Wei-Chun Chin ${ }^{4}$, Chih-Hong Lo ${ }^{5}$, Tsann-Long Hwang ${ }^{5}$, Chia-Ming Yang ${ }^{1,25, *}$ and \\ Chao-Sung Lai $2,6,7$ \\ 1 Institute of Electro-Optical Engineering, Chang Gung University, Taoyuan 333, Taiwan; \\ miraculous0218@hotmail.com (P.-Y.L.); wendy326446@gmail.com (Y.-J.L.); \\ enjoytw8555@gmail.com (Y.-P.C.) \\ 2 Department of Electronic Engineering, Chang Gung University, Taoyuan 333, Taiwan; \\ hl120121219@gmail.com (H.-L.L.); cslai@mail.cgu.edu.tw (C.-S.L.) \\ 3 Department of Medical Biotechnology and Laboratory Science, Chang Gung University, Taoyuan 333, \\ Taiwan; purpleeri@gmail.com (T.-R.-W.); hclai@mail.cgu.edu.tw (H.-C.L.) \\ 4 Bioengineering Department, University of California, Merced, CA 95343, USA; wchin2@ucmerced.edu \\ 5 Department of General Surgery, Chang Gung Memorial Hospital at Linkou, Taoyuan 333, Taiwan; \\ albertloch@gmail.com (C.-H.L.); hwangtl@cloud.cgmh.org.tw (T.-L.H.) \\ 6 Department of Nephrology, Chang Gung Memorial Hospital at Linkou, Taoyuan 333, Taiwan \\ 7 Department of Materials Engineering, Ming Chi University of Technology, New Taipei City 24301, Taiwan \\ * Correspondence: cmyang@mail.cgu.edu.tw; Tel.: +886-3-211-8800 (ext. 5960) \\ + Presented at the Eurosensors 2018 Conference, Graz, Austria, 9-12 September 2018. \\ Published: 16 November 2018
}

\begin{abstract}
To investigate the ion activities of cells based on light-addressable potentiometric sensor (LAPS) platform, various high-dielectric constant sensing membrane were investigated the visibility and potential issue. Three different kinds of well-proven materials in semiconductor industry, such as $\mathrm{Si}_{3} \mathrm{~N}_{4}, \mathrm{NbOx}$, and $\mathrm{TiN}$, are the promising sensing membranes to directly culture C3A cells. TiN and $\mathrm{NbOx}$ could be the potential candidate. The photocurrent and flatband voltage difference generated by acidification reaction is verified to observe by LAPS is the future.
\end{abstract}

Keywords: C3A; chemical image; LAPS

\section{Introduction}

Light-addressable potentiometric sensor (LAPS) was proposed as the platform to obtain the 2D images of cells [1]. Some cells were proven to be cultured on sensing membrane of LAPS, which may need an optimization in the culture process since the material properties changes from glass dish $[2,3]$. However some issues including apoptosis in culture could be found in the measurement procedure. In this study, 3 different high-dielectric constant materials were fabricated on LAPS device to verify the possibility of cell culture.

\section{Materials and Methods}

The process flow and schematic plot of sensor structure were shown in Figure 1. The P-type Si wafer was used as semiconductor of LAPS. For LAPS with $\mathrm{Si}_{3} \mathrm{~N}_{4}$ and TiN sensing membrane, a buffer layer of thermally-grown $\mathrm{SiO}_{2}$ was fabricated firstly. Both $\mathrm{Si}_{3} \mathrm{~N}_{4}$ [4] and $\mathrm{TiN}$ [5] were proven as a good sensing membrane in field-effect sensors. However $\mathrm{NbOx}$ layer was directly deposited on Si surface $[5,6]$. Then an encapsulation with a polydimethyl-siloxane (PDMS) tank with a design of 2layer Proceedings 2018, 2, 1021, doi:10.3390/proceedings2131021 www.mdpi.com/journal/proceedings 
structure was attached to high-dielectric constant layer as the container for cell culture. The bottom layer with 4 small wells and the top layer with 1 big well are used for LAPS measurement and cell culture, respectively. An epithelium cell line of human liver cancer, HepG2/C3A, is cultured directly on LAPS within the area of 4 wells. Culture medium MEM contains 10\% fetal bovine serum was used for maintenance. Culture medium was refreshed every 2 days and then subculture once a week then incubated in $37^{\circ} \mathrm{C}$ and $5 \% \mathrm{CO}_{2}$. After cultured, the response of $\mathrm{C} 3 \mathrm{~A}$ cells could be measured by the photocurrent versus bias voltage curves of LAPS system [6].
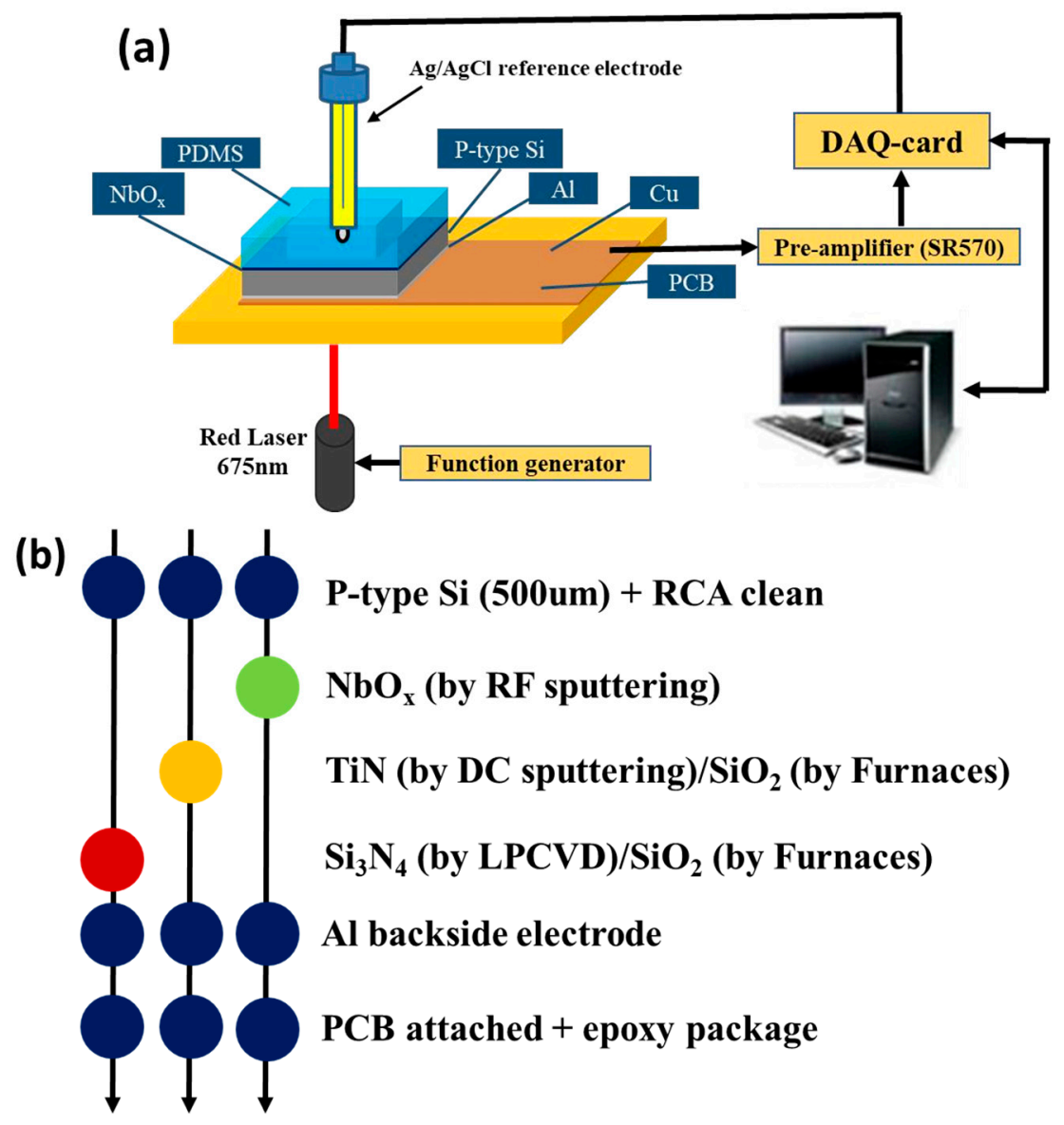

Figure 1. (a) Schematic plot of 3 device structures and (b) its process flow.

\section{Results \& Discussion}

First of all, seeding different number of C3A cells on each sample for 24 to $48 \mathrm{~h}$. After cultured in the same incubator, optical microscope (OM) pictures with $\mathrm{C} 3 \mathrm{~A}$ cells cultured on different surface is shown in Figure 2a-d. It can be clearly seen C3A cells could be cultured well on glass dish. The health status of $\mathrm{C} 3 \mathrm{~A}$ cells on high-dielectric constant could be in the rank as TiN $>\mathrm{NbOx}>\mathrm{Si}_{3} \mathrm{~N}_{4}$ layer. It could be a good reference of surface status to the photovoltage versus bias voltage curves. As shown in Figure 3a, photocurrent versus bias voltage curves of 3 different sensors could be clearly observed. With thinner insulator layer, higher photovoltage could be found. The shift between standard buffer solution of $\mathrm{pH} 2$ and 12 could be used to calculated the $\mathrm{pH}$ sensitivity. The largest shift could be found in NbOx, which is matched to expectations. Cell acidification for $30 \mathrm{~min}$ from the medium changes to HBSS will make the photovoltage versus bias voltage curves shift negative bias in the $\mathrm{Si}_{3} \mathrm{~N} 4 / \mathrm{SiO}_{2}$ LAPS as shown in Figure 3b. With the lower $\mathrm{pH}$ value of sensing membrane surface, the photovoltage versus bias voltage will be shifted to negative bias based on the mechanism of LAPS operation. Current data shows $\mathrm{Si}_{3} \mathrm{~N}_{4}$ membrane is acceptable for cell culture. Other material should be investigated to match cell properties in culture process. This proposed methodology could be further investigated to get 2D images of cell status and the following toxicity and drug test. 
(a)

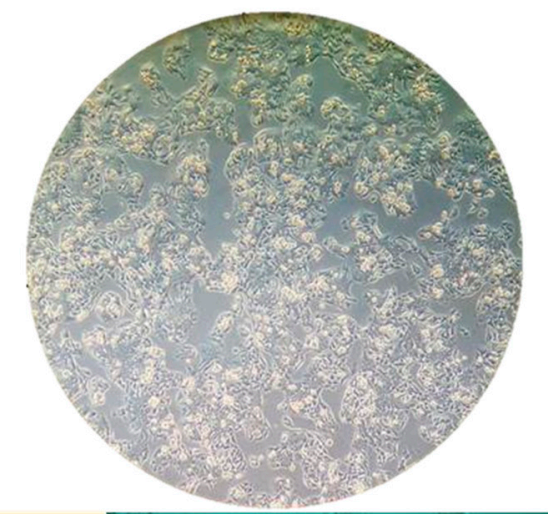

(c) $\mathrm{NbO}_{\mathbf{x}}$

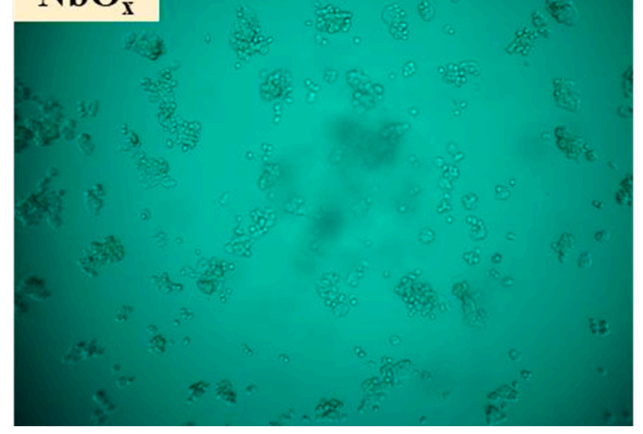

(b)

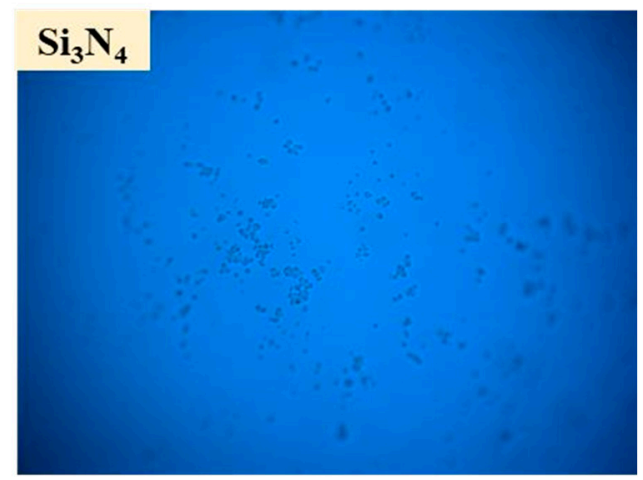

(d)

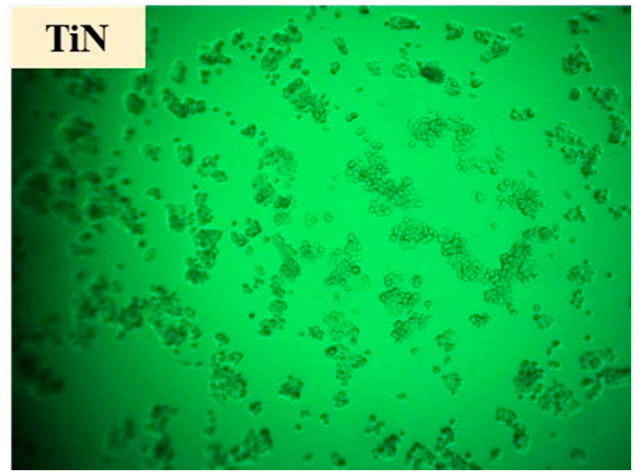

Figure 2. C3A cell images on (a) culture dish, (b) $\mathrm{Si}_{3} \mathrm{~N}_{4},(\mathbf{c}) \mathrm{NbOx}$ and (d) $\mathrm{TiN} / \mathrm{SiO}_{2} \mathrm{LAPS}$ surface.
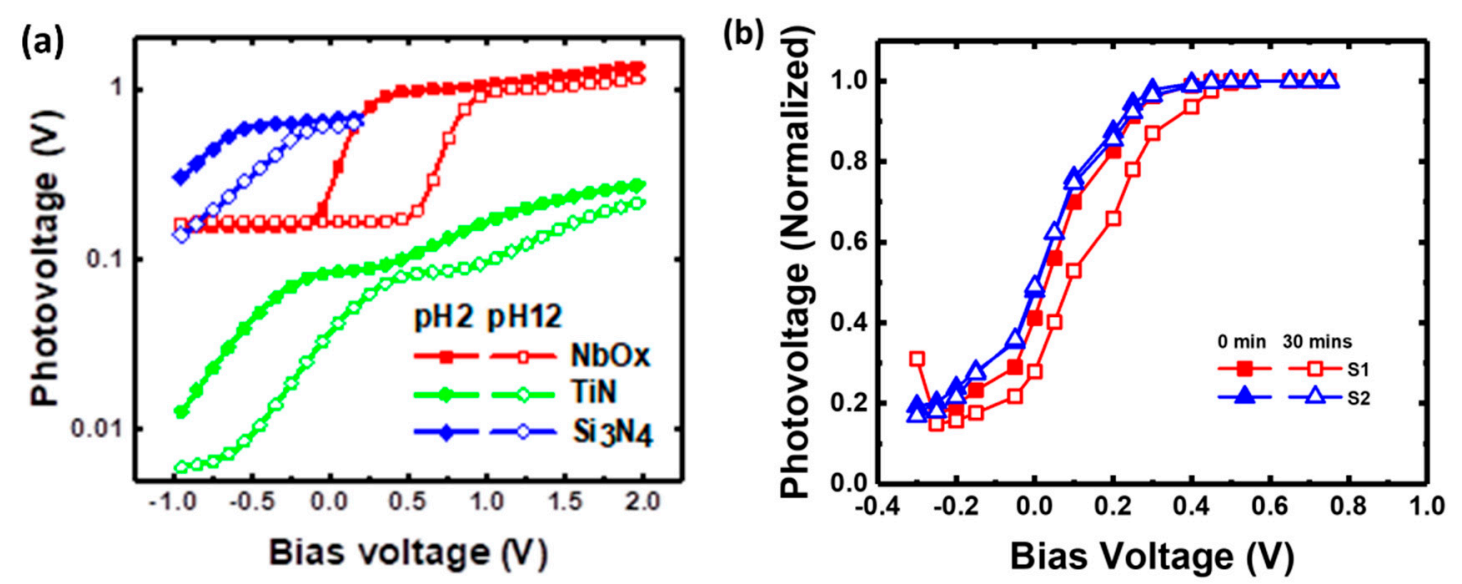

Figure 3. (a) photovoltage versus bias voltage curves of 3 different device structure. (b) photocurrent of $\mathrm{C} 3 \mathrm{~A}$ cells acidification behavior on $\mathrm{Si}_{3} \mathrm{~N}_{4}$ membrane after seeding $2.5 \times 10^{4}$ on each sample for $48 \mathrm{~h}$.

\section{Conclusions}

Firstly, 3 different high-dielectric constant materials of LAPS are applied as the surface of cell culture. Direct cell culture on these membranes shows big differences on the optical microscope images. In the meantime, photovoltage versus bias voltage measured by LAPS system could be used to monitor the cell acidification with a negative shift in bias voltage after $30 \mathrm{~min}$. This platform could be a potential tool to evaluate the cell status and relatively drug effects.

Author Contributions: T.-L.H., C.-M.Y., and C.-S.L. conceived and designed the experiments; P.-Y.L., Y.-J.L., Y.P.C. performed the experiments; W.-C.C., C.-H.L., T.-L.H., C.-M.Y., and C.-S.L. analyzed the data; T.-R.W. and H.-C.L. contributed reagents/materials/analysis tools; C.-M.Y. wrote the paper.

Acknowledgments: This research was partially supported by the Ministry of Science and Technology of the Republic of China under Contract no. MOST 105-2221-E-182-057-MY3. 
Conflicts of Interest: The authors declare no conflict of interest.

\section{References}

1. Dantism, S.; Takenaga, S.; Wagner, T.; Wagner, P.; Schöning, M.J. Differential imaging of the metabolism of bacteria and eukaryotic cells based on light-addressable potentiometric sensors. Electrochim. Acta 2017, 246, 234-241.

2. Zhang, D.W.; Wu, F.; Wang, J.; Watkinson, M.; Krause, S. Image detection of yeast Saccharomyces cerevisiae by light-addressable potentiometric sensors (LAPS). Electrochem. Commun. 2016, 72, 41-45.

3. Wang, J.; Du, L.; Krause, S.; Wu, C.; Wang, P. Surface modification and construction of LAPS towards biosensing applications. Sens. Actuators. B Chem. 2018, 265, 161-173.

4. Yang, C.M.; Zeng, W.Y.; Chen, Y.P.; Chen, T.C. Surface modification for high photocurrent and pH sensitivity in a silicon-based light-addressable potentiometric sensor. IEEE Sens. J. 2018, 18, 2253-2259.

5. Yang, C.M.; Zeng, W.Y.; Chen, C.H.; Chen, Y.P.; Chen, T.C. Spatial resolution and 2D chemical image of light-addressable potentiometric sensor improved by inductively coupled-plasma reactive-ion etching. Sens. Actuators B Chem. 2018, 258, 1295-1301.

6. Yang, C.M.; Chiang, T.W.; Yeh, Y.T.; Das, A.; Lin, Y.T.; Chen, T.C. Sensing and pH-imaging properties of niobium oxide prepared by rapid thermal annealing for electrolyte-insulator-semiconductor structure and light-addressable potentiometric sensor. Sens. Actuators B Chem. 2015, 207, 858-864.

(C) 2018 by the authors; Licensee MDPI, Basel, Switzerland. This article is an open access article distributed under the terms and conditions of the Creative Commons Attribution (CC BY) license (http://creativecommons.org/licenses/by/4.0/). 